\title{
Multi-omics reveals mitochondrial metabolism proteins susceptible for drug discovery in AML
}

\author{
Mika Caplan (D) ${ }^{1,2}$, Karli J. Wittorf ${ }^{1,2}$, Kasidy K. Weber ${ }^{1,2}$, Samantha A. Swenson (D) ${ }^{1,2}$, Tyler J. Gilbreath ${ }^{1,2}$, R. Willow Hynes-Smith ${ }^{1,2}$, \\ Catalina Amador ${ }^{2,3}$, R. Katherine Hyde ${ }^{2,4}$ and Shannon M. Buckley $\mathbb{D}^{1,2 \bowtie}$
}

(c) The Author(s) 2022

Acute myeloid leukemia ( $A M L)$ is a devastating cancer affecting the hematopoietic system. Previous research has relied on RNA sequencing and microarray techniques to study the downstream effects of genomic alterations. While these studies have proven efficacious, they fail to capture the changes that occur at the proteomic level. To interrogate the effect of protein expression alterations in AML, we performed a quantitative mass spectrometry in parallel with RNAseq analysis using AML mouse models. These combined results identified 34 proteins whose expression was upregulated in AML tumors, but strikingly, were unaltered at the transcriptional level. Here we focus on mitochondrial electron transfer proteins ETFA and ETFB. Silencing of ETFA and ETFB led to increased mitochondrial activity, mitochondrial stress, and apoptosis in AML cells, but had little to no effect on normal human $\mathrm{CD}_{3}{ }^{+}$cells. These studies identify a set of proteins that have not previously been associated with leukemia and may ultimately serve as potential targets for therapeutic manipulation to hinder AML progression and help contribute to our understanding of the disease.

Leukemia (2022) 36:1296-1305; https://doi.org/10.1038/s41375-022-01518-z

\section{INTRODUCTION}

Acute myeloid leukemia (AML) affects the hematopoietic system through abnormal proliferation of myeloid cells in the bone marrow (BM) and ultimately suppresses the production of healthy blood cells. AML is the leading cause of death among adult leukemia patients, although it represents only $35 \%$ of those diagnosed [1]. Disease initiation often occurs through recurrent genetic aberrations resulting in the formation of oncogenic fusion proteins [1, 2]. Two genomic alterations found in patients are Mixed Lineage Leukemia (MLL) rearrangements and an inversion of chromosome $16(\operatorname{Inv}(16))$ [3-6].

The protein histone-lysine N-methyltransferase $2 \mathrm{~A}(\mathrm{KMT} 2 \mathrm{~A})$, also known as the mixed-lineage leukemia 1 (MLL1) gene, contains domains essential for transcriptional activity and chromatin modifications during early hematopoiesis, and fusion proteins generated from each translocation lead to aberrant transcription of MLL target genes [7-11]. MLL1 has been found to have 80 different fusion partners, although only a few are commonly linked with AML [2]. AML::MLL rearrangements account for $10 \%$ of all diagnosed leukemias and these subtypes typically tend to have worse patient prognoses [12-14].

The Inv(16) subtype of AML represents approximately $6 \%$ of adults and $9 \%$ of pediatric patients [15]. Inv(16) AML results in a fusion between core-binding factor subunit beta $(C B F B)$ and myosin heavy chain 11 (MYH11) [16, 17]. The resulting fusion protein, CBF $3:: S M M H C$, through dimerization with the hematopoietic transcription factor RUNX1 leads to a block in myeloid differentiation [16, 18]. Typically, patients diagnosed with this subtype of AML tend to have a more positive prognosis as the cancer is less aggressive for those included in this cytogenetic profile compared to their MLL-rearranged counterparts.

Although multiple advancements in the field have been direct results of the identification and characterization of many AMLinitiating mutations, the mechanisms by which the cancer progresses remain ambiguous. While many studies have attempted to investigate these mechanisms through a series of RNA-based methods, these studies have left out potential implications relating to changes that occur at the proteomic level. Our study was designed to specifically interrogate the effect of altered protein expression in AML progression by combining RNAsequencing (RNA-seq) techniques with a quantitative mass spectrometry (MS) analysis in mouse models of AML: CBFB:: MYH11 (Inv(16)), MLL::AF9, and MLL::ENL. These AML translocations were purposefully chosen to highlight the differences in prognosis and potentially identify targets that are differentially or commonly expressed across all translocations. This would allow us to further speculate that targets shared across these AML translocations may also be common among others and could be useful for future

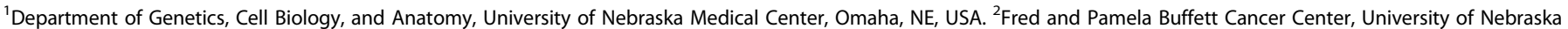

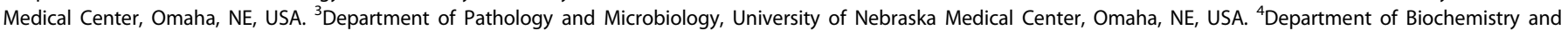
Molecular Biology, University of Nebraska Medical Center, Omaha, NE, USA. ${ }^{凶}$ email: Shannon.Buckley@unmc.edu

Received: 22 May 2021 Revised: 12 January 2022 Accepted: 31 January 2022

Published online: 17 February 2022 
therapeutic studies targeting a heterogeneous group of AML translocations. With these combined results, we identified 34 upregulated proteins from AML tumors that remained unaltered at the transcriptional level. These proteins were shown to be associated with mitochondrial function as well as RNA processing. In addition, analysis of adult and pediatric AML patient expression data sets revealed that a number of the proteins differentially expressed had no significant RNA expression alterations. Most notably, we found that mitochondrial proteins ETFA and ETFB were overexpressed in all three translocations and could potentially share a role in the progression of the disease.

AML treatment has remained mostly unchanged for the last few decades, consisting of intensive induction chemotherapy generally a combination of cytarabine and an anthracycline, such as daunorubicin, with the occasional addition of all trans-retinoic acid (ATRA) for certain subtypes [2, 19-21]. A number of treatments have progressed to clinical trials, but only in recent years have any been approved by the Food and Drug Administration, however, most are limited to specific subtypes of AML and only improves the treatment options for limited subsets of patients [22-25]. Up to $50 \%$ of patients treated with intensive induction therapy fail to achieve complete remission and are classified as primary refractory or resistant [26]. These studies identify a set of proteins that have not previously been associated with leukemia and may ultimately serve as potential targets for therapeutic manipulation to hinder AML progression and contribute to our understanding of this disease.

\section{MATERIALS AND METHODS}

\section{AML mouse models}

To induce expression of Cbfb::MYH11, 6-8 week-old floxed mice and littermate controls received three intraperitoneal Poly $(\mathrm{l}: \mathrm{C})$ injections every other day at a dose of $10 \mu \mathrm{g} / \mathrm{g}$ (Invivogen, San Diego, CA, USA) [27]. MLL:: AF9 mice were purchased from Jackson Laboratory (\#009079, Bar Harbor, ME, USA) [28]. To produce the MLL::ENL mouse model, Lineage- Sca- $1^{+}$ $\mathrm{CKit}^{+}$(LSK) cells from wild-type (WT) mice were sorted and infected with MLL::ENL (Addgene\#20873) retrovirus by spinning for $1 \mathrm{~h}$ at 3000 RPM. $48 \mathrm{~h}$ post-infection LSKs were transplanted with 200,000 WT BM into lethally irradiated WT mice (1000 cGy). Mice were sacrificed when they exhibited signs of disease and/or demonstrated a high white blood cell (WBC) count. cKit/Gr1/CD11 b ${ }^{+}$tumor cells and $\mathrm{CKit}^{+}{ }^{+}$WT cells were isolated by positive magnetic selection using Mojo Sort beads following manufacturers protocol (BioLegend).

For transplants of AML cell lines, $5 \times 10^{5}$ MOLM-13 cells were transplanted into sub-lethally $(250 \mathrm{cGy})$ irradiated NOD.Cg-Prkdc scid $1 / 2 \mathrm{rg}^{\text {tmiWjil} / S z J}$ (NSG) mice (\#005557, Jackson Labs). All experiments performed were approved by the Institutional Animal Care and Use Committee of the University of Nebraska Medical Center in accordance with $\mathrm{NIH}$ guidelines.

\section{Flow cytometry analysis}

Cells were stained for $1 \mathrm{~h}$ on ice with antibodies in 3\% FBS in PBS. For apoptosis, staining was performed following BioLegend apoptosis staining protocol and stained with AnnexinV and propidium iodine.

\section{Patient datasets and samples}

ETFA and ETFB expression and survival analyses in patients utilized data from the publicly available Microarray Innovations in Leukemia (MILE) [29], Therapeutically Applicable Research to Generate Effective Treatments (TARGET) [4], and TGCA Genomic and Epigenomic Landscapes of Adult De Nove Acute Myeloid Leukemia [6] studies. Samples and statistics were previously described [30]. Human $\mathrm{CD}_{3} 4^{+}$cells were purchased from the Fred Hutch Hematopoietic Cell Procurement and Processing Services Core, and primary AML samples were purchased from Cureline Translational CRO (Supplementary Table 1).

\section{Cell culture and shRNA lentiviral transduction}

HL-60, KASUMI-1, and MOLM-13 cells were purchased and cultured as recommended by ATCC and DSMZ, respectively. All cells were confirmed mycoplasma negative prior to use. Human $\mathrm{CD}_{3} 4^{+}$cells were cultured in StemSpan SFEM II media with $\mathrm{CD} 34^{+}$Expansion Supplement (StemCell Technologies) for $24 \mathrm{~h}$ prior to viral infection. The pLKO.1 shRNA plasmid vectors were purchased from Sigma-Aldrich. Lentivirus was produced following manufacturer's instructions. Cells were infected as previously described and treated with $1 \mu \mathrm{g} / \mathrm{ml}$ of puromycin $48 \mathrm{~h}$ post infection. Assays were performed 5 days after initial puromycin treatment. MOLM-13 cells were treated for $72 \mathrm{~h}$ with $0.1-50 \mathrm{nM}$ venetoclax and analyzed by MTT assay, and for flow cytometry analysis cells were treated with $5 \mathrm{nM}$ venetoclax for $48 \mathrm{~h}$.

\section{Immunofluorescence/Western blot}

Cells were seeded onto Poly-L-Lysine coverslips (Corning). Cells were fixed at room temp (RT) for $15 \mathrm{~min}$ with $4 \% \mathrm{w} / \mathrm{v}$ paraformaldehyde followed by permeabilization and blocking with $3 \% \mathrm{w} / \mathrm{v}$ goat serum and $0.2 \% \mathrm{v} / \mathrm{v}$ Triton X-100 in PBS for 30 min at RT. Cells were stained with primary antibody for $1 \mathrm{~h}$ followed by goat anti-rabbit IgG AlexaFluor594 or goat anti-mouse IgG AlexaFluor488 (ThermoFisher Scientific) for $45 \mathrm{~min}$. Confocal imaging was performed using a Zeiss LSM 800 confocal microscope with a $63 \mathrm{X} / 1.4$ numerical aperture oil objective.

Western blot analysis was performed as previously described [31]. Antibodies were prepared in 5\% BSA in TBST as indicated in supplemental materials and methods.

\section{RNA isolation, qRT-PCR, and RNA-sequencing}

Total RNA was extracted using the Monarch Total RNA Miniprep Kit (New England Biolabs, Ipswich, MA, USA). cDNA was synthesized using High Capacity RNA-to-cDNA Kit (ThermoFisher) followed by qRT-PCR. Primers in supplemental materials and methods. RNA sequencing was performed by Novogene. RNAseq analysis was performed by UNMC Bioinformatics Core Facility, and are publicly available on NIH GEO with the dataset identifier GSE193366.

\section{TMT labeling and mass spectrometry}

For global proteome quantification, splenic tumor cells and WT $\mathrm{cKit}^{+}$ samples were prepared and TMT-labeled per manufacturer's protocol (ThermoFisher TMT10plex Mass Tag Labeling Kits), and processed as previously described [31]. The mass spectrometry proteomics data have been deposited to the ProteomeXchange Consortium via the PRIDE partner repository with the dataset identifier PXD025628 [32].

\section{Mitochondrial respiration}

Oxygen consumption rate was assayed using Cell Mito Stress kit (Agilent) and analyzed on Seahorse XF HS mini analyzer.

\section{Electron microscopy}

Cell pellets were fixed in $2 \%$ glutaraldehyde, $2 \%$ paraformaldehyde in $0.1 \mathrm{M}$ Sorensen's phosphate buffer, pH7.2. Samples were post fixed in $1 \%$ osmium tetroxide in water, dehydrated, and embedded. 60 to 90 nanometer sections were placed on 200 mesh copper grids (Ted Pella). Sections were stained with $2 \%$ Uranyl Acetate and Reynolds' lead citrate for 5 min each step. Sections were examined with a Technai G2 Transmission Electron Microscope (FEI) operated at $80 \mathrm{Kv}$ with an AMT camera for digital imaging.

\section{Statistical analysis}

All experiments were performed in triplicate unless noted and statistical analyses were performed using unpaired two-tailed Student's $t$ tests assuming experimental samples of equal variance. Center values represent mean, and error bars depict standard deviation. ${ }^{*} p$ value $<0.05,{ }^{* *} p$ value $<0.01,{ }^{* * *} p$ value $<0.001,{ }^{* * * *} p$ value $<0.0001$

\section{Additional materials and methods}

Antibodies, primers, and additional methods are provided in the Supplementary Material.

\section{RESULTS}

\section{Quantitative mass spectrometry performed in combination} with RNA-seq analysis

To compare AML tumors at the transcriptional and translational levels, we utilized 3 different mouse models of AML. To study MLL 

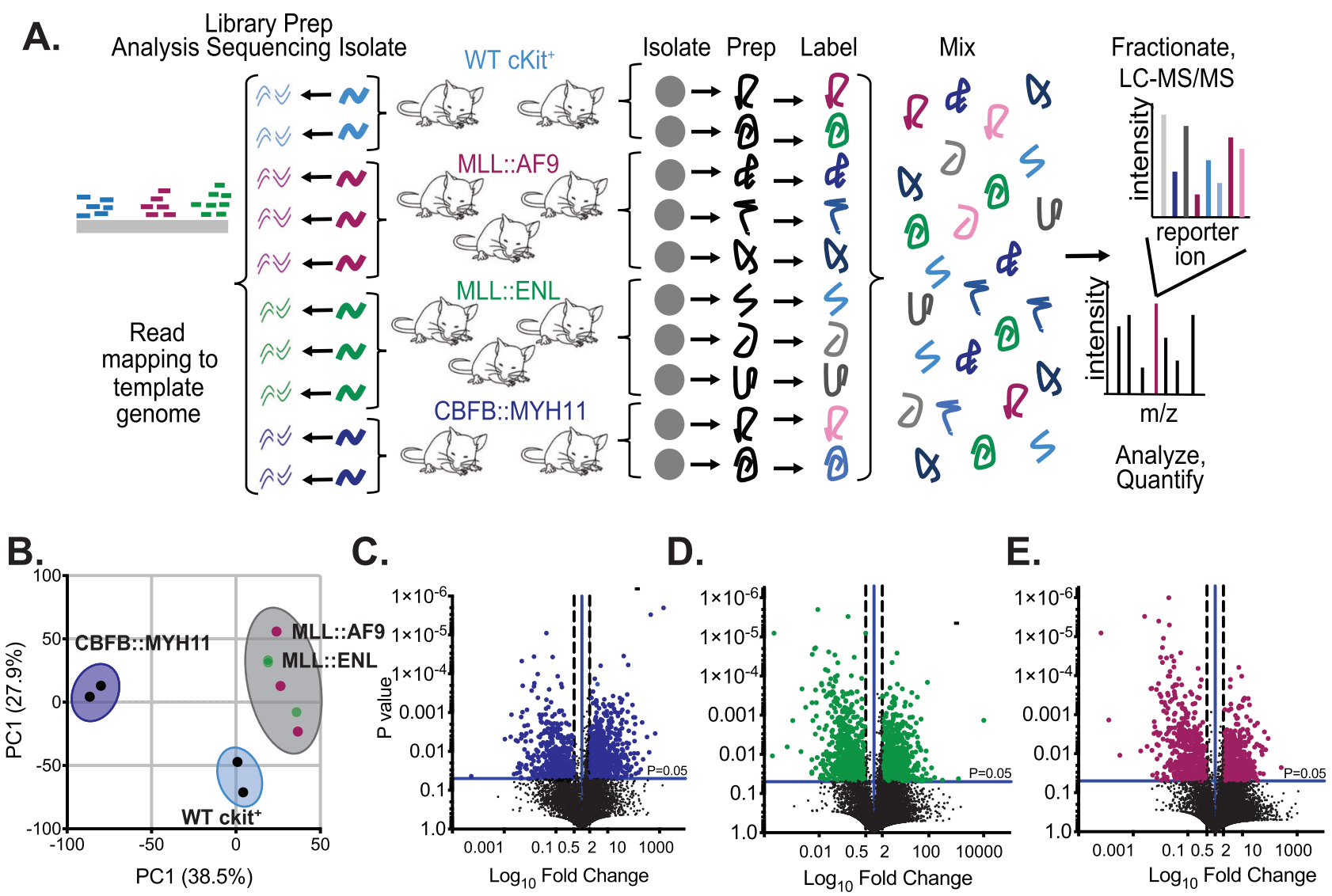

Fig. 1 Utilizing AML mouse models to compare proteome vs transcriptome. A Preparation schematic for TMT MS and RNA-seq using spleen tumors isolated from mice expressing MLL::AF9 $(n=3)$, MLL::ENL $(n=3)$, CBFB::MYH1 $(n=2)$ and $\mathrm{CKit}^{+}$BM of WT mice $(n=2)$. B Principal component analysis of WT cKit ${ }^{+}$cells compared to MLL::AF9, MLL::ENL, and CBFB::MYH11 tumors. Volcano plots showing fold change of expressed genes from C CBFB::MYH11, D MLL::ENL, and E MLL::AF9 tumors compared to WT cKit ${ }^{+}$cells.

translocations, we utilized MLL::AF9 transgenic mice and MLL::ENL mice generated by retroviral transduction of the fusion protein into hematopoietic stem and progenitor cells (HSPC) [28, 33]. Cbfb::MYH11 tumors were generated by crossing $\mathrm{Mx}-1 \mathrm{Cre}{ }^{+}$mice with Cbfb::MYH11 (Cbfb $\left.{ }^{+/ 56 M}\right)$ floxed mice, which allows for inducible expression of CBF $\beta:: S M M H C$ (Inv(16)) following administration of Poly(l:C) [27]. Mouse AML populations are heterogenous and can be similar to immature HSPC which is marked by expression of the cKit receptor [34], but can also be more similar to terminally differentiated myeloid cells $\left(\mathrm{Gr}-1^{+} / \mathrm{CD} 11 \mathrm{~b}^{+}\right)$. WT $\mathrm{cKit}^{+} \mathrm{BM}$ cells were selected to compare with mouse tumors due to the importance of identifying therapeutic targets that do not affect survival of normal HSPC (Fig. 1A). A total of 10 mice were used for analysis: two WT, three MLL::AF9, three MLL::ENL, and two Cbfb::MYH11. While MLL translocations generally express more mature myeloid cell surface markers such as Gr1 and Mac1 (CD11b), the Cbfb::MYH11 translocation is characterized by an immature marker, cKit (Supplementary Fig. 1A). Tumor burden within the spleen varied between 40 to $98 \%$, and were purified by positive magnetic selection utilizing anti-cKit, Gr1, and Mac1 (CD11b) antibodies for a more homogenous tumor population (Supplementary Fig. 1A). The 3 different mouse models of AML had similar survival, and all translocations succumbed to disease within the expected period between 20 and 41 weeks (Supplementary Fig. 1B). The mouse models of AML were utilized to perform an RNA-sequencing experiment in parallel with a Tandem Mass Tag (TMT)-labeled mass spectrometry analysis. Proteins from each mouse were isolated for mass spectrometry and in parallel, we isolated RNA from the tumors to prepare for RNA sequencing (Fig. 1A). These initial analyses allowed for the characterization of each sample used in this study to directly compare AML translocations that represented varying outcomes of prognosis.

RNA-seq identifies differentially expressed genes among AML translocations CBFB::MYH11 (Inv(16)), MLL::AF9, and MLL::ENL Analysis from RNA-sequencing identified 21,180 expressed genes in the AML mouse tumors and $\mathrm{CKit}^{+} \mathrm{BM}$ cells. Of these, 3,430 were significantly upregulated or downregulated compared to WT mice. Principal component analysis (PCA) of the genes expressed found that all six of the MLL tumors clustered together, suggesting an overall similarity and lack of distinction across the two MLL translocations, whereas Cbfb::MYH11 tumors clustered separately from the MLL tumors (Fig. 1B). Differentially expressed genes shared across all three translocations demonstrated that the two MLL translocations shared far more differentially expressed genes (149 and 176; upregulated and downregulated, respectively) than with the Cbfb::MYH11 translocation (86 and 46; upregulated, 62 and 32; downregulated), suggesting more similarity between these AML subtypes. Although MLL::AF9 and MLL::ENL are both MLL translocations, they only shared 149 upregulated genes in common, suggesting heterogeneity even among MLL tumors (Fig. 1C-E). Taken together, the RNA-seq results identified genes that were differentially expressed within the AML translocations and revealed more similar patterns of RNA expression among MLL translocations.

TMT-Labeled MS identifies differentially expressed proteins among AML translocations CBFB::MYH11 (Inv(16)), MLL::AF9, and MLL::ENL

We next evaluated the proteome of the AML mouse tumors. Quantitative mass spectrometry analysis identified 28,708 unique 

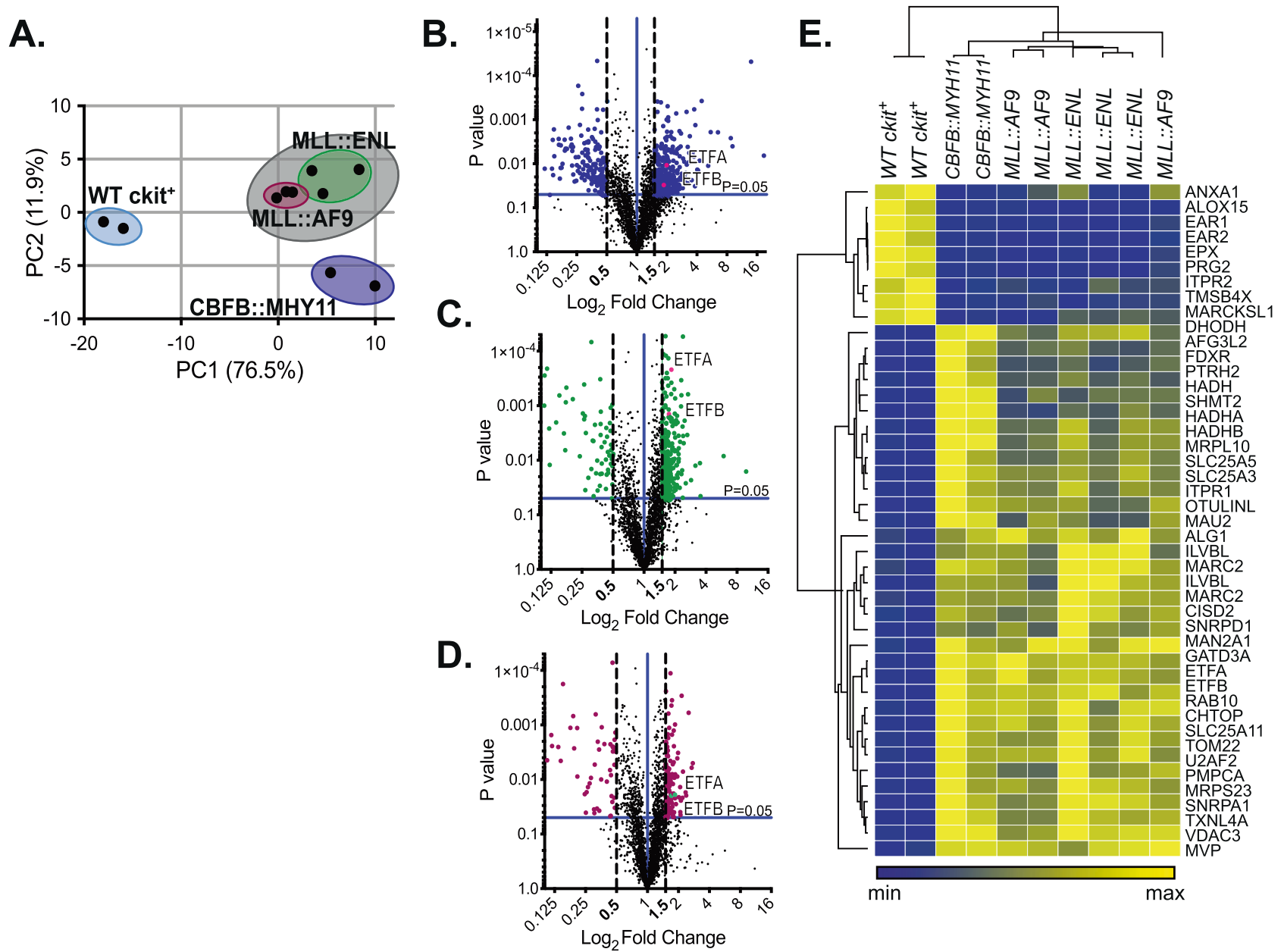

Fig. 2 TMT-Labeled MS identifies differentially expressed proteins among AML translocations CBFB::MYH11, MLL::AF9, and MLL::ENL. A Principal component analysis of WT cKit ${ }^{+}$cells compared to MLL::AF9, MLL::ENL, and CBFB::MYH11 tumors. Volcano plots showing fold change of expressed proteins from B CBFB::MYH11 (Inv(16)), C MLL::ENL, and D MLL::AF9 tumors compared to WT cKit ${ }^{+}$cells. E Heatmap with hierarchical clustering of the significantly upregulated $(p<0.05, \geq 1.5$-fold increase over WT) and downregulated $(p<0.05, \leq 0.5$-fold decrease from WT) proteins.

peptides representing 4743 proteins of which 4312 were quantifiable. Only proteins with three or more unique peptides were considered for analysis and of these, 797 were either upregulated or downregulated in at least one of the AML translocations compared to WT. PCA analysis between each translocation found that tumor samples from MLL::AF9 and MLL::ENL clustered separately, indicating a greater level of distinction in expression pattern at the protein level (Fig. 2A). Protein comparison revealed 9 downregulated and 34 upregulated proteins shared among all three translocations, suggesting a greater level of similarity at the protein level for multiple AML translocations (Supplementary Tables 2 and 3). We further compared protein expression of each translocation to WT using volcano plots and found that MLL translocations shared a similar pattern of protein expression when compared to WT for proteins that were upregulated $(p<0.05$, fold change $\geq 1.5$ ) or downregulated $(p<0.05$, fold change $\leq 0.5$ ) (Fig. 2B-D). Differentially expressed proteins overall clustered by AML translocation (Fig. 2E). These results revealed a contrastingly different pattern of protein expression when comparing each AML translocation as well as identified commonly upregulated and downregulated proteins of interest.

\section{Comparison of RNA and protein expression reveals} differentially expressed proteins shared among data sets In order to fully compare between genes and proteins expressed among AML translocations, we compared total number of identified proteins with total number of RNA transcripts and found an overlap of 2,729 proteins. Moreover, we compared total number of differentially expressed proteins with differentially expressed genes and interestingly found that 42 proteins were not differentially expressed at the RNA level (Fig. 3A). Of these 42 differentially expressed proteins, we found that 34 were upregulated and 8 were downregulated in all three translocations. The 34 upregulated proteins were associated with a number of pathways, including RNA splicing and mitochondrial processes (Fig. 3B, Supplementary Tables 2-4) [35]. We further investigated the upregulated proteins identified to examine cellular locations, expression levels, and previously found associations with leukemia (Supplementary Tables 3 and 4). Two novel electron transport proteins: electron transfer flavoprotein subunit $\alpha$ and $\beta$ (ETFA and ETFB) were significantly overexpressed in tumors from all three AML translocations while their transcripts were unaltered. These findings reveal a set of proteins that are altered distinctly at the proteomic level, with many that are significantly upregulated and participate in key regulatory processes of the cell.

Electron transfer proteins ETFA and ETFB are differentially expressed as proteins, but are unaltered in RNA-seq and RNA patient data

ETFA and ETFB are heterodimeric mitochondrial proteins that form a complex with one flavin adenine dinucleotide (FAD) and one 
A.

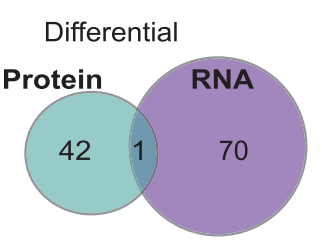

B.

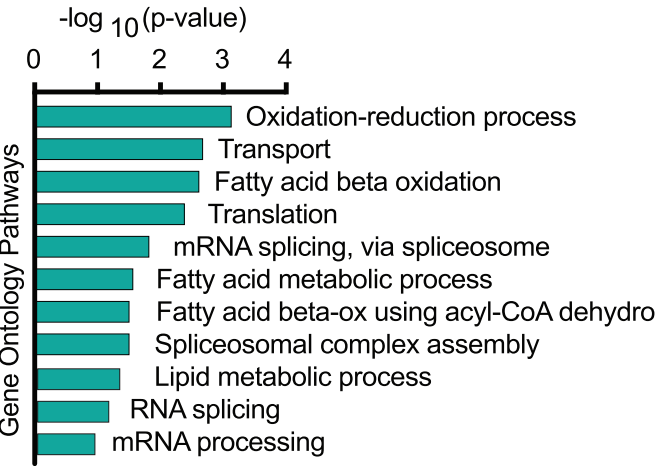

Fig. 3 Comparison of RNA and protein expression reveals 42 differentially expressed proteins shared among AML translocations. A Combined MS and RNA-seq data comparing overlap of total differentially expressed proteins and genes. B Gene ontology analysis showing pathways known to be associated with significantly upregulated ( $p<0.05, \geq 1.3$-fold change) proteins using DAVID bioinformatics database.

adenosine monophosphate (AMP) [36] to complete the electron transfer flavoprotein (ETF). They are involved in mitochondrial fatty acid and amino acid metabolism by transferring electrons between flavoprotein dehydrogenases. Rare biallelic mutations in ETFA and ETFB seen in infants to young adults are associated with multiple acyl-CoA dehydrogenase (MADD) deficiencies [37]. MADD is a heterogenous disorder that ranges from infant lethality to late onset with mild phenotype. ETFA and ETFB have not previously been associated with AML; however, AML cells have increased mitochondrial mass and low respiratory chain activity leading them to be sensitive to mitochondrial stress [38]. In addition, the electron transport chain (ETC) complex I has been targeted in AML therapeutics $[39,40]$. Validation of RNA and protein expression in mouse tumors confirmed that both ETFA and ETFB show high protein expression but no difference at the RNA level compared to WT cKit ${ }^{+}$cells (Fig. 4A, B). Patient-derived AML cell lines $\mathrm{HL}-60$, MOLM-13, and KASUMI-1 were compared with $\mathrm{CKit}^{+}$lysate for protein expression of ETFA and ETFB (Fig. 4B). Analysis of patient data from the Leukemia MILE study revealed similar findings to mouse RNA-seq and showed that in adults, most AML subsets have either no significant difference or even significantly decreased gene expression of ETFA and ETFB compared to healthy bone marrow (Fig. 4C) [29]. As AML is the second most common childhood leukemia, we utilized the TARGET pediatric study to analyze ETFA and ETFB expression and again found downregulation or no significant change of ETFA and ETFB in most subtypes of AML (Supplementary Fig. 2A) [4]. Expression of ETFA did not correlate with the probability of patient survival; however, both adult and pediatric patients with high ETFB expression had poor survival (Fig. 4D, Supplementary Fig. 2B). A cohort of 5 primary human $A M L$ samples ranging from $\mathrm{MO}-\mathrm{M} 4$ also exhibited low expression of ETFA by RNA but high expression at the protein level (Fig. 4E, F). These findings suggest similar patterns of expression of ETFA and ETFB proteins across multiple translocations of human AML and further support the idea that ETFA and ETFB may be potential therapeutic targets in AML.

\section{Silencing of ETF leads to mitochondrial stress}

Consistent with the localization of mitochondrial protein TOM20 in HELA cells, ETFA and ETFB proteins are localized to mitochondria (Supplementary Fig. 3A, B). In order to determine the role of ETFA and ETFB expression in $A M L$, we utilized shRNA expressing lentivirus in MOLM-13 and HL-60 AML cell lines. MOLM-13 cells have the MLL::AF9 translocation whereas HL-60 cells do not contain common AML translocations [41-43]. ETFA and ETFB are heterodimers and, interestingly, silencing of either component led to decreased expression at both the RNA and protein level suggesting they may be regulated transcriptionally and posttranscriptionally in a dependent manner (Fig. 5A, B;
Supplementary Figs. 3C-E and 4A). Silencing of ETFA and ETFB in MOLM-13 cells did not alter mitochondrial localization or expression of TOM20 (Fig. 5A). To determine if depletion of ETFA altered mitochondrial ultrastructure, we performed electron microscopy in MOLM-13 ETFA and ETFB knockdown cells. In mitochondria silenced for ETFA or ETFB, we observed a high frequency of damaged mitochondria (as indicated by arrows) (Fig. 5C).

We next asked whether knockdown of ETFA and ETFB alters mitochondrial function. To evaluate mitochondrial metabolism, we performed Seahorse to determine mitochondrial respiration. We found that silencing of ETFA and ETFB in AML cell lines led to increased oxygen consumption rate $(\mathrm{OCR})$, respiration, extracellular acidification rate (ECAR), ATP production, and spare respiratory capacity (Fig. 5D-G; Supplementary Fig. 4B-G). Taken together, this suggests that AML cell function is sensitive to EFTA and ETFB depletion and inhibition leads to increased mitochondrial metabolism and damages mitochondria.

\section{AML cells, but not human $\mathrm{CD} 34^{+}$normal cells, are sensitive to ETFA and ETFB silencing}

To further understand the impact of ETFA and ETFB depletion in AML cell lines, we analyzed cell proliferation, survival, and differentiation. Silencing of ETFA and ETFB in MOLM-13 and HL60 cells led to decreased proliferation and ability to generate colony-forming units as well as increased apoptosis and cell death measured by Annexin $\mathrm{V}$ and propidium iodine (PI) (Fig. 6A-C; Supplementary Fig. $4 \mathrm{H}-\mathrm{I}$ ). Of note, silencing ETFA and ETFB in HELA cells did not alter survival of the cells (data not shown). Depletion led to increased expression of Mac1 (CD11b), a marker of mature myeloid cells (Fig. 6D). MOLM-13 cells expressing ETFA and ETFB shRNA were transplanted into immune-deficient NSG mice (Fig. 6E). Mice transplanted with cells expressing the control shRNA succumbed to AML an average of 10 days post-transplant whereas cells expressing an shRNA targeting ETFA and ETFB led to mice living significantly longer (Fig. 6E). These studies demonstrate that proliferation and survival of AML cells is dependent on high ETFA and ETFB protein expression. The impact of ETFA and ETFB on proliferation, survival, and mitochondrial stress all contribute to the ability of the cells to engraft, expand and generate disease in the NSG mouse model.

In $\mathrm{AML}$, the $\mathrm{B}$ cell lymphoma 2 (BCL-2) protein is highly expressed and plays a role in AML survival by binding pro-apoptotic proteins and inhibiting mitochondrial-induced apoptosis. Currently, venenoclax, a BCL-2 inhibitor has proven efficacious, however some patients develop resistance [44]. To determine whether mitochondrial stress from inhibiting ETFA/B would lead to increased sensitivity to venetoclax, we treated shRNA-targeted MOLM-13 cells with increasing concentrations of venetoclax. Silencing of either ETFA or 
A.
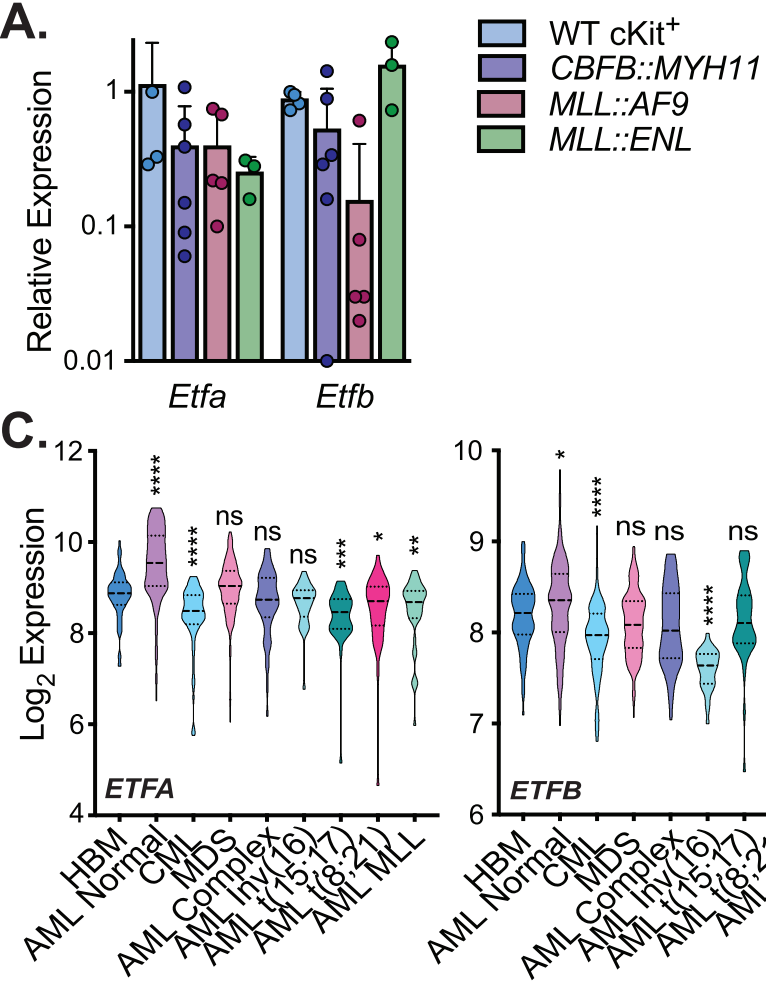

MLL:::ENL

E.

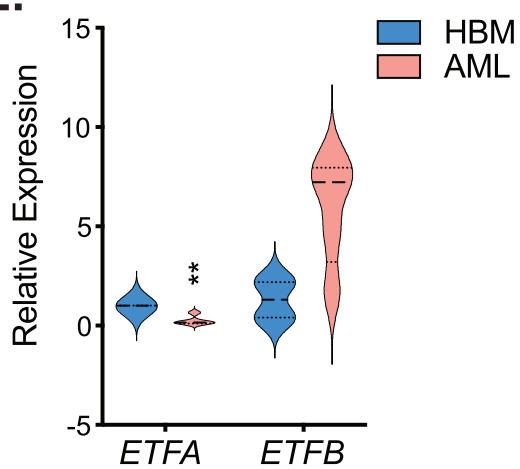

F.
B.

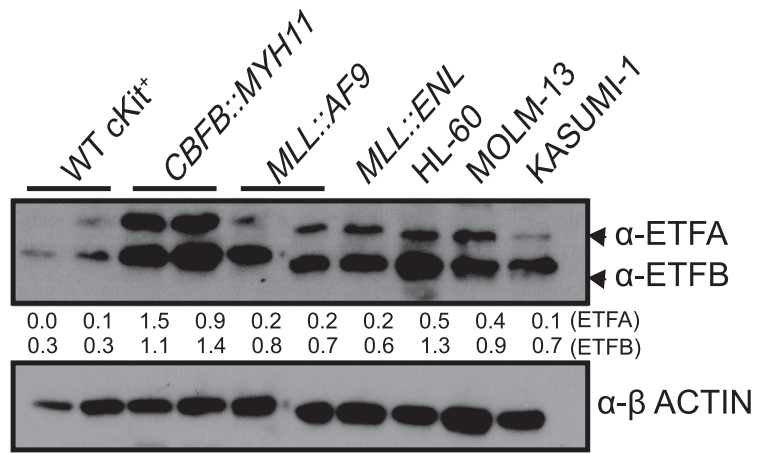

D.
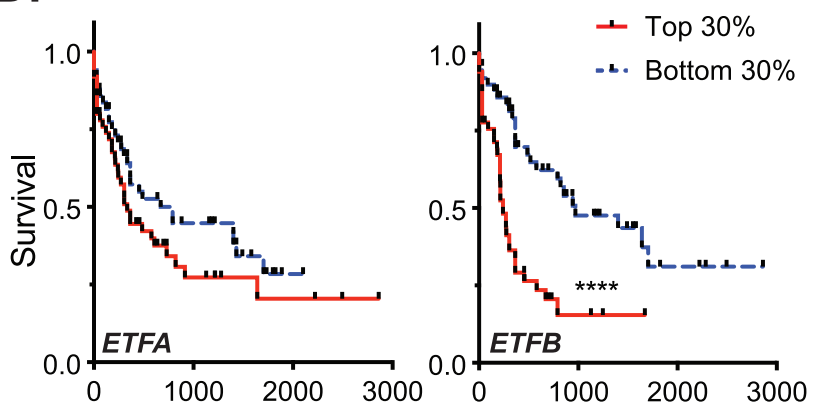

Days

Days

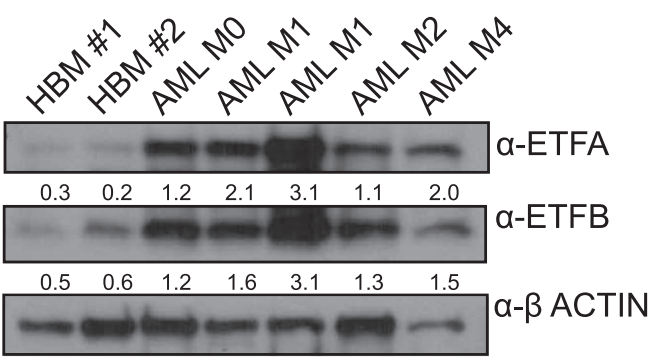

Fig. 4 Electron transfer proteins ETFA and ETFB are differentially expressed as proteins but are unaltered as RNA. A qRT-PCR for mRNA expression of Etfa and Etfb in AML mouse tumors $(n=3-6)$. B Western blot probing for ETFA and ETFB in mouse AML tumors and in patientderived AML cell lines compared with mouse $\mathrm{CKit}^{+}$WT BM lysate. C ETFA and ETFB gene expression analysis of patient samples from the MILE study. D Overall survival from TCGA AML patient dataset analyzing patients with the highest $30 \%$ and lowest $30 \%$ of ETFA and ETFB expression. E qRT-PCR and $\mathbf{F}$ western blot from 2 independent human BM samples and 5 primary patient AML samples (Supplementary Table 1). $\left({ }^{*} p<0.05,{ }^{* *} p<0.01,{ }^{* * *} p<0.001,{ }^{* * * *} p<0.0001\right.$, ns non-significant).

ETFB reduced the IC:50 to $4.1 \mathrm{nM}$ and $4.7 \mathrm{nM}$, respectively, and lead to increased apoptosis (Fig. 6F, Supplemental Fig. 4J). Together, these studies suggest that silencing of ETFA and ETFB promotes mitochondrial stress leading to increased apoptosis, decreased proliferation, and sensitivity to venetoclax.

AML cells were sensitive to depletion of ETFA and ETFB; however, it is important to understand the impact on normal HSPC. In order to determine the effect of silencing ETFA and ETFB on human HSPC, we performed knockdown experiments in human $\mathrm{CD}_{3} 4^{+}$cells isolated from mobilized PB. Similarly to the AML cell lines, we utilized shRNAs targeting ETFA and ETFB, and cultured the cells in media containing cytokines to promote proliferation, but maintained the $\mathrm{CD}_{3} 4^{+}$population. We observed similar knockdown efficiency in $\mathrm{CD}_{3}{ }^{+}$cells (Fig. 6G). However, unlike in AML cell lines, silencing ETFA and ETFB did not lead to differentiation, loss of colony-forming potential, or impacted proliferation (Fig. $6 \mathrm{H}-\mathrm{I}$ ). In addition, we did not see elevated frequency of apoptosis following knockdown, suggesting normal cells are less sensitive to inhibition of ETFA and ETFB (Supplemental Fig. 4K, L). Together these findings suggest that targeting mitochondrial metabolism by interfering with ETFA and ETFB could be a potential therapeutic approach for AML without affecting normal HSPC.

\section{DISCUSSION}

Combining mass spectrometry and RNA-seq analyses in mouse models of $A M L$, we were able to identify a sub-set of proteins that 
A.
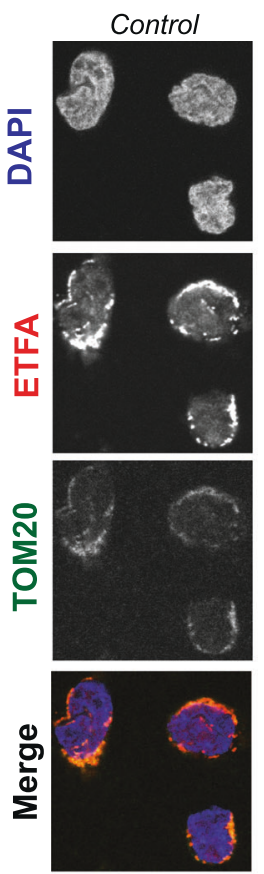

D.

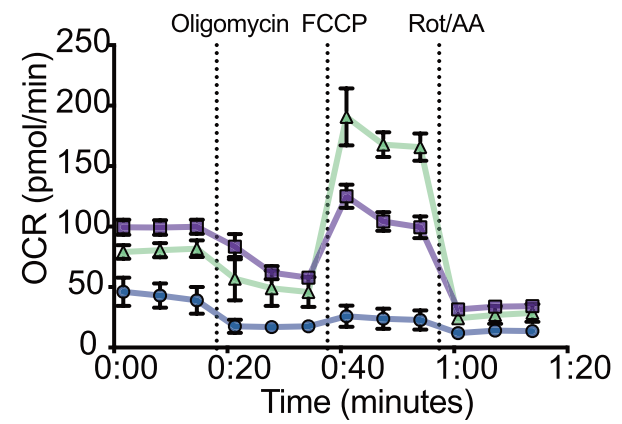

- Control $\square$ ETFA.15 $\triangle$ ETFB.29
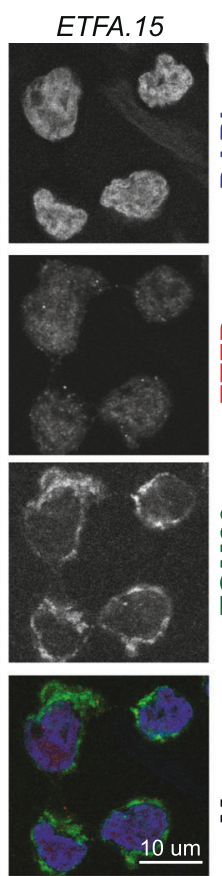

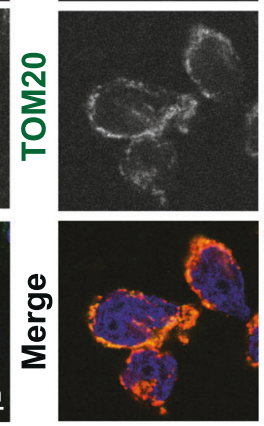

E.
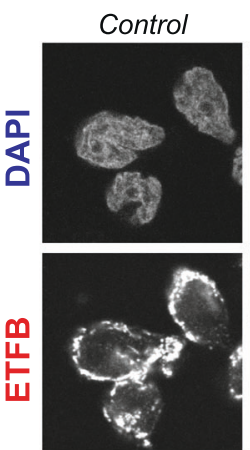

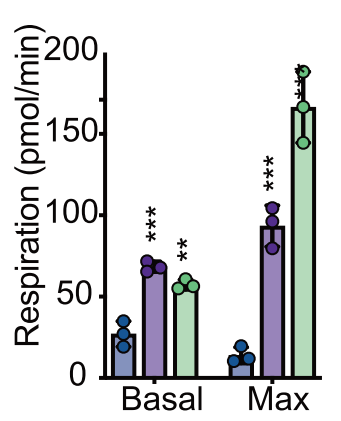

B.

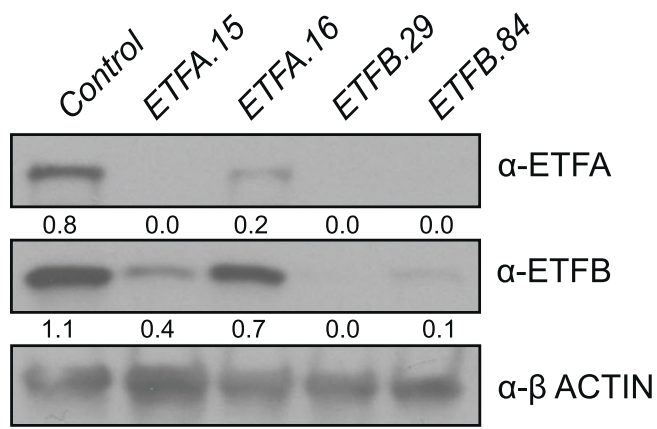

C.

ETFA. 15

ETFB.29

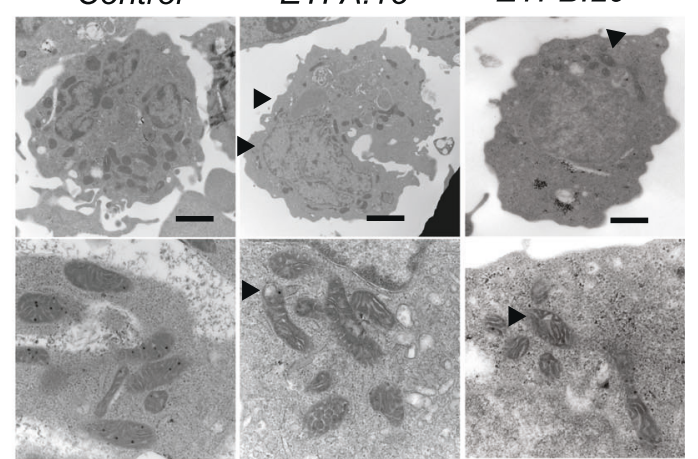

F.

G.

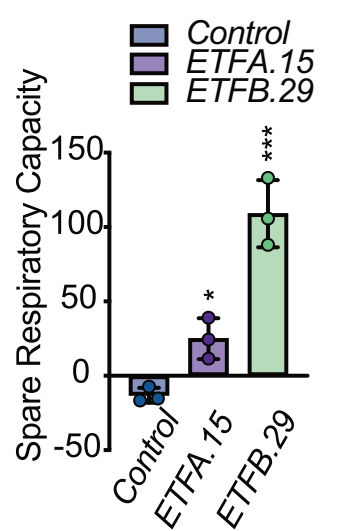

Fig. 5 Inhibition of ETFA and ETFB leads to mitochondrial stress. A-G MOLM-13 cells were lentivirally infected with shRNAs targeting ETFA and ETFB or non-targeting control, and analyzed 72 hours post puromycin selection. Changes in expression analyzed by A immunofluorescence with mitochondrial protein, TOM20, and B western blot of ETFA and ETFB. C Electron microscopy following silencing of ETFA and ETFB. Analysis of changes in $\mathbf{D}$ oxygen consumption rate (OCR), $\mathbf{E}$ basal and maximum respiration rate, $\mathbf{F}$ ATP production, and G spare respiratory capacity by seahorse following knockdown of either ETFA or ETFB. $\left({ }^{*} p<0.05,{ }^{* *} p<0.01,{ }^{* * *} p<0.001\right.$, $\left.{ }^{* * * *} p<0.0001\right)$.

have limited or no alterations in transcript levels compared to their normal counterparts. These upregulated proteins play a role in RNA splicing and mitochondrial processes - two processes currently under investigation for therapeutic targeting and are relied on for AML survival [38, 45-47]. It is believed that leukemic stem cells (LSCs) rely heavily on oxidative phosphorylation (OXPHOS) and metabolic mechanisms of the mitochondria in order to maintain self-renewal and survival [48-50]. Many proteins implicated in these pathways have become novel therapeutic targets and recent studies show that inhibiting parts of mitochondrial metabolism severely impairs the ability of leukemic cells to survive [39, 40, 51]. A recently approved AML drug, venetoclax, targets the mitochondrial protein $\mathrm{BCL}-2$ for inhibition and has seen some success in survival and remission rate; however, many patients have become resistant to venetoclax treatment [52]. Previous research has shown that inhibiting key mitochondrial proteins in venetoclax-resistant AML has relieved some of the acquired resistance, suggesting that targeting additional mitochondrial proteins, including ETFA and ETFB, may be useful as a therapeutic strategy [45]. In our study we find that silencing of ETFA and ETFB leads to mitochondrial stress, differentiation, apoptosis, and increased sensitivity to venetoclax. These cellular processes combined most likely impede disease initiation and engraftment of the AML cells in NSG mice.

Some of the additional differentially expressed proteins identified from this study correspond with regulators of splicing and spliceosome components. Recently, mutations in genes coding for components of the spliceosome have been found to correlate with certain hematopoietic malignancies, including AML $[46,53-57]$. Two predominantly mutated spliceosome proteins (SF3B1 and U2AF1) were both determined to be differentially expressed in the AML models in this study $[55,56,58-60]$. SF3B1 is mutated in a variety of hematopoietic malignancies and these mutations often lead to changes in splice site recognition and splicing components of the protein rather than resulting in a lossof-function mutation [46, 54,57]. U2AF1 is another splicing protein 
A.

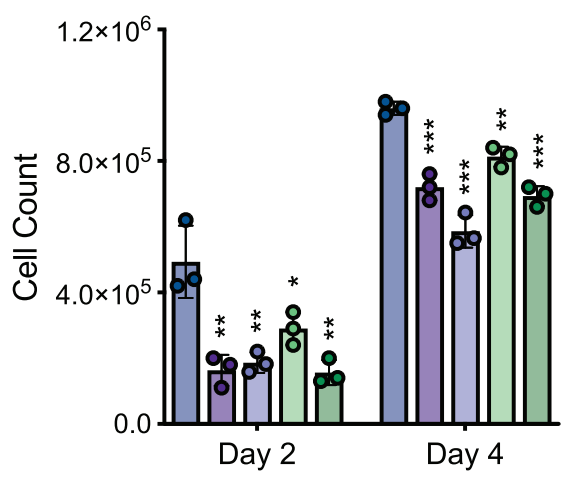

B.

E.
C.

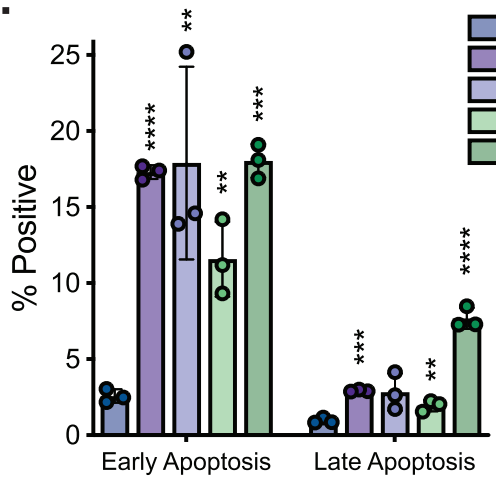

(2)

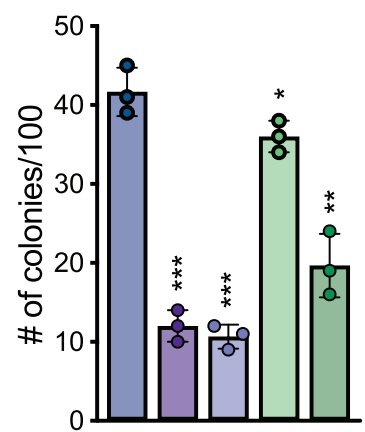

F.
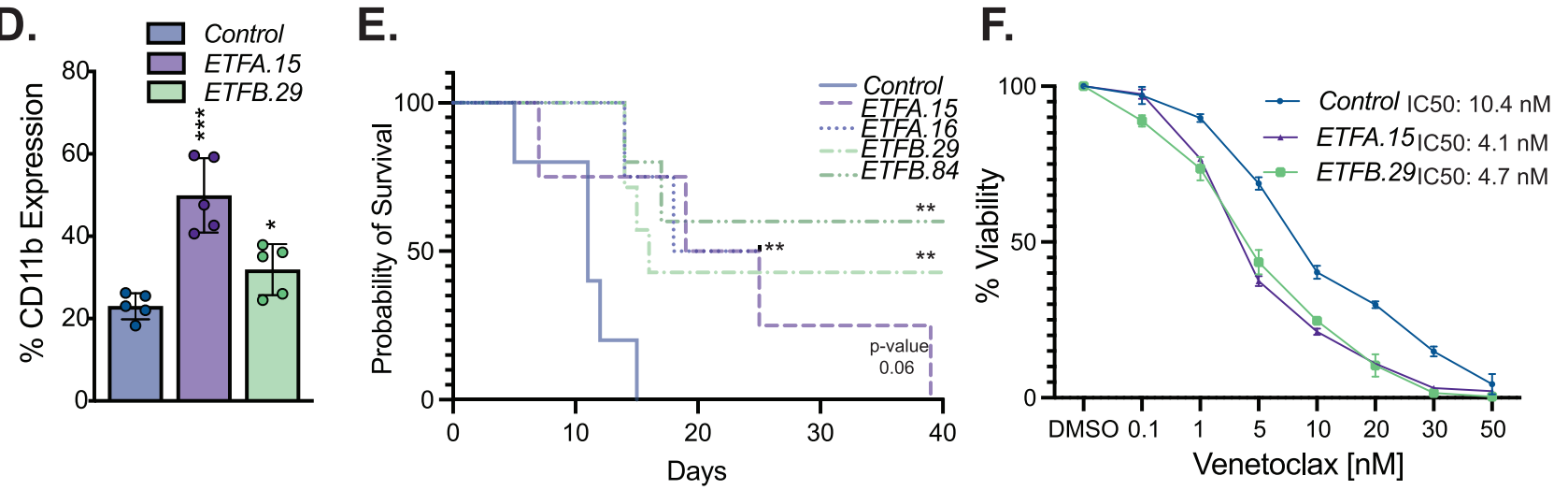

G.

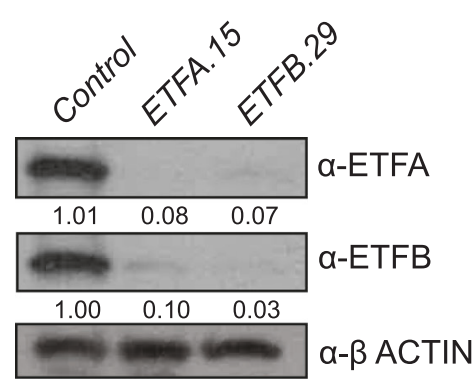

H.

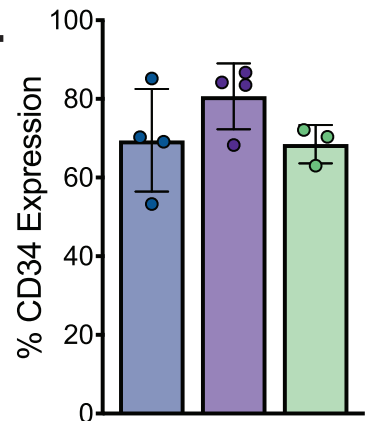

1.

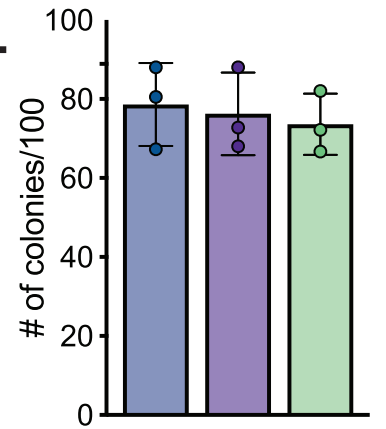

\section{,} .

Fig. 6 Silencing of ETFA and ETFB leads to decreased proliferation and survival in AML cells but not in normal human CD34 ${ }^{+}$cells. A-F Differences between MOLM-13 cells lentivirally infected with shRNAs targeting ETFA and ETFB or non-targeting control. $72 \mathrm{~h}$ post puromycin selection were analyzed by A cell counts at day 2 and day 4, B ability to form colonies in colony-forming units (CFU) assay, C Annexin V and PI staining for percent apoptotic cells, D CD11 b expression by flow cytometry, and $\mathbf{E}$ survival rate of sub-lethally irradiated NSG mice transplanted with $5 \times 10^{5}$ MOLM-13 cells infected with shRNAs targeting ETFA and ETFB or non-targeting control. $\mathbf{F}$ MTT assay following treatment with 0.1-50 nM venetoclax for $72 \mathrm{~h}$. G-I Human PB mobilized CD34 ${ }^{+}$cells from 3 independent donors were infected with lentivirus expressing scramble control or shRNAs targeting ETFA and ETFB and analyzed $72 \mathrm{~h}$ post puromycin selection for $\mathbf{G}$ knockdown by western blot, H CD34 expression by flow cytometry, and I ability to form colonies in CFU assay $(N=3)$.

specifically required for the recognition of the AG-dinucleotide sequence at the $3^{\prime}$ end of mRNA [59]. Commonly found mutations have led to changes in splicing such as cassette exon skipping/ inclusion in targets of the spliceosome, leading to downstream alterations in important cellular pathways. Targeting components of the spliceosome has been one promising area of research in $\mathrm{AML}$, although the mechanisms by which these splicing factors affect hematopoietic malignancies must be further investigated.

Overall, the hits identified from our RNA-seq and MS analyses allow for a continued effort to investigate the roles of these proteins in AML and other hematopoietic malignancies and to understand how they may contribute to the dysregulation of cancer cells. Importantly, silencing of ETFA and ETFB had minimal impact on survival, maintenance, and differentiation to the HSPC population, suggesting that targeting ETFA and ETFB would not lead to hematopoietic failure. Although further validation and examination is needed, these hits may ultimately serve as potential therapeutic targets in future studies relating to AML.

\section{REFERENCES}

1. Dohner H, Weisdorf DJ, Bloomfield CD. Acute myeloid leukemia. N Engl J Med. 2015;373:1136-52.

2. Dohner H, Estey EH, Amadori S, Appelbaum FR, Buchner T, Burnett AK, et al. Diagnosis and management of acute myeloid leukemia in adults: recommendations from an international expert panel, on behalf of the European LeukemiaNet. Blood. 2010;115:453-74.

3. Sood R, Hansen NF, Donovan FX, Carrington B, Bucci D, Maskeri B, et al. Somatic mutational landscape of $A M L$ with inv(16) or $t(8 ; 21)$ identifies patterns of clonal evolution in relapse leukemia. Leukemia. 2016;30:501-4. 
4. Farrar JE, Schuback HL, Ries RE, Wai D, Hampton OA, Trevino LR, et al. Genomic profiling of pediatric acute myeloid leukemia reveals a changing mutational landscape from disease diagnosis to relapse. Cancer Res. 2016;76:2197-205.

5. Duployez N, Marceau-Renaut A, Boissel N, Petit A, Bucci M, Geffroy S, et al. Comprehensive mutational profiling of core binding factor acute myeloid leukemia. Blood. 2016;127:2451-9.

6. Cancer Genome Atlas Research N, Ley TJ, Miller C, Ding L, Raphael BJ, Mungall AJ, et al. Genomic and epigenomic landscapes of adult de novo acute myeloid leukemia. N Engl J Med. 2013;368:2059-74.

7. Prange KHM, Mandoli A, Kuznetsova T, Wang SY, Sotoca AM, Marneth AE, et al. MLL-AF9 and MLL-AF4 oncofusion proteins bind a distinct enhancer repertoire and target the RUNX1 program in 11q23 acute myeloid leukemia. Oncogene. 2017;36:3346-56.

8. Milne TA, Dou Y, Martin ME, Brock HW, Roeder RG, Hess JL. MLL associates specifically with a subset of transcriptionally active target genes. Proc Natl Acad Sci USA. 2005;102:14765-70.

9. McMahon KA, Hiew SY, Hadjur S, Veiga-Fernandes H, Menzel U, Price AJ, et al. Mll has a critical role in fetal and adult hematopoietic stem cell self-renewal. Cell Stem Cell. 2007;1:338-45.

10. Jude $C D$, Climer L, Xu D, Artinger E, Fisher JK, Ernst P. Unique and independent roles for MLL in adult hematopoietic stem cells and progenitors. Cell Stem Cell. 2007;1:324-37.

11. Antunes ETB, Ottersbach K. The MLL/SET family and haematopoiesis. Biochim Biophys Acta Gene Regul Mech. 2020;1863:194579.

12. Li X, Song Y. Structure, function and inhibition of critical protein-protein interactions involving mixed lineage leukemia 1 and its fusion oncoproteins. J Hematol Oncol. 2021;14:56.

13. Kelly LM, Gilliland DG. Genetics of myeloid leukemias. Annu Rev genomics Hum Genet. 2002;3:179-98.

14. Ferrara F, Schiffer CA. Acute myeloid leukaemia in adults. Lancet 2013:381:484-95.

15. Schuback HL, Arceci RJ, Meshinchi S. Somatic characterization of pediatric acute myeloid leukemia using next-generation sequencing. Semin Hematol. 2013;50:325-32.

16. Castilla LH, Garrett L, Adya N, Orlic D, Dutra A, Anderson S, et al. The fusion gene Cbfb-MYH11 blocks myeloid differentiation and predisposes mice to acute myelomonocytic leukaemia [letter]. Nat Genet. 1999;23:144-6.

17. Liu $P$, Tarle SA, Hajra A, Claxton DF, Marlton P, Freedman $M$, et al. Fusion between transcription factor CBF beta/PEBP2 beta and a myosin heavy chain in acute myeloid leukemia. Science. 1993;261:1041-4.

18. Hyde RK, Zhao L, Alemu L, Liu PP. Runx1 is required for hematopoietic defects and leukemogenesis in Cbfb-MYH11 knock-in mice. Leukemia. 2015;29:1771-8.

19. Armand P, Kim HT, Logan BR, Wang Z, Alyea EP, Kalaycio ME, et al. Validation and refinement of the Disease Risk Index for allogeneic stem cell transplantation. Blood. 2014;123:3664-71.

20. Gupta V, Tallman MS, Weisdorf DJ. Allogeneic hematopoietic cell transplantation for adults with acute myeloid leukemia: myths, controversies, and unknowns. Blood. 2011;117:2307-18.

21. Sorror ML, Storb RF, Sandmaier BM, Maziarz RT, Pulsipher MA, Maris MB, et al. Comorbidity-age index: a clinical measure of biologic age before allogeneic hematopoietic cell transplantation. J Clin Oncol. 2014;32:3249-56.

22. Castaigne S, Pautas C, Terre C, Raffoux E, Bordessoule D, Bastie JN, et al. Effect of gemtuzumab ozogamicin on survival of adult patients with de-novo acute myeloid leukaemia (ALFA-0701): a randomised, open-label, phase 3 study. Lancet. 2012:379:1508-16.

23. Lancet JE, Rizzieri D, Schiller GJ, Stuart RK, Kolitz JE, Solomon SR, et al. Overall survival (OS) with CPX-351 versus $7+3$ in older adults with newly diagnosed, therapy-related acute myeloid leukemia (tAML): Subgroup analysis of a phase III study. J Clin Oncol. 2017;35:7035. 15_suppl

24. Stein EM, DiNardo CD, Pollyea DA, Fathi AT, Roboz GJ, Altman JK, et al. Enasidenib in mutant $\mathrm{IDH} 2$ relapsed or refractory acute myeloid leukemia. Blood. 2017;130:722-31.

25. Stone RM, Mandrekar SJ, Sanford BL, Laumann K, Geyer S, Bloomfield CD, et al. Midostaurin plus chemotherapy for acute myeloid leukemia with a FLT3 mutation. N Engl J Med. 2017;377:454-64.

26. Thol F, Schlenk RF, Heuser M, Ganser A. How I treat refractory and early relapsed acute myeloid leukemia. Blood. 2015;126:319-27.

27. Kuo YH, Landrette SF, Heilman SA, Perrat PN, Garrett L, Liu PP, et al. Cbf betaSMMHC induces distinct abnormal myeloid progenitors able to develop acute myeloid leukemia. Cancer Cell. 2006;9:57-68.

28. Corral J, Lavenir I, Impey H, Warren AJ, Forster A, Larson TA, et al. An MII-AF9 fusion gene made by homologous recombination causes acute leukemia in chimeric mice: a method to create fusion oncogenes. Cell. 1996;85:853-61.

29. Haferlach T, Kohlmann A, Wieczorek L, Basso G, Kronnie GT, Bene MC, et al. Clinical utility of microarray-based gene expression profiling in the diagnosis and subclassification of leukemia: report from the International Microarray Innovations in Leukemia Study Group. J Clin Oncol. 2010;28:2529-37.

30. Hynes-Smith RW, Swenson SA, Vahle H, Wittorf KJ, Caplan M, Amador C, et al. Loss of FBXO9 enhances proteasome activity and promotes aggressiveness in acute myeloid leukemia. Cancers. 2019;11;1717.

31. Swenson SA, Gilbreath TJ, Vahle $\mathrm{H}$, Hynes-Smith RW, Graham JH, Law HC, et al. UBR5 HECT domain mutations identified in mantle cell lymphoma control maturation of B cells. Blood. 2020;136:299-312.

32. Deutsch EW, Csordas A, Sun Z, Jarnuczak A, Perez-Riverol Y, Ternent T, et al. The ProteomeXchange consortium in 2017: supporting the cultural change in proteomics public data deposition. Nucleic Acids Res. 2017;45:D1100-D6.

33. Bach C, Mueller D, Buhl S, Garcia-Cuellar MP, Slany RK. Alterations of the CxxC domain preclude oncogenic activation of mixed-lineage leukemia 2. Oncogene. 2009;28:815-23.

34. Morrison SJ, Uchida N, Weissman IL. The biology of hematopoietic stem cells. Annu Rev Cell Dev Biol. 1995;11:35-71.

35. Dennis G Jr, Sherman BT, Hosack DA, Yang J, Gao W, Lane HC, et al. DAVID: database for annotation, visualization, and integrated discovery. Genome Biol. 2003;4:P3.

36. Roberts DL, Frerman FE, Kim JJ. Three-dimensional structure of human electron transfer flavoprotein to 2.1-A resolution. Proc Natl Acad Sci USA. 1996:93:14355-60.

37. Olsen RK, Andresen BS, Christensen E, Bross P, Skovby F, Gregersen N. Clear relationship between ETF/ETFDH genotype and phenotype in patients with multiple acyl-CoA dehydrogenation deficiency. Hum Mutat. 2003;22:12-23.

38. Sriskanthadevan $S$, Jeyaraju DV, Chung TE, Prabha $S$, Xu W, Skrtic M, et al. AML cells have low spare reserve capacity in their respiratory chain that renders them susceptible to oxidative metabolic stress. Blood. 2015;125:2120-30.

39. Cole A, Wang Z, Coyaud E, Voisin V, Gronda M, Jitkova Y, et al. Inhibition of the mitochondrial protease ClpP as a therapeutic strategy for human acute myeloid leukemia. Cancer Cell. 2015;27:864-76.

40. Baccelli I, Gareau Y, Lehnertz B, Gingras S, Spinella JF, Corneau S, et al. Mubritinib targets the electron transport chain complex I and reveals the landscape of OXPHOS dependency in acute myeloid leukemia. Cancer Cell. 2019;36:84-99 e8.

41. Gallagher R, Collins S, Trujillo J, McCredie K, Ahearn M, Tsai S, et al. Characterization of the continuous, differentiating myeloid cell line (HL-60) from a patient with acute promyelocytic leukemia. Blood. 1979;54:713-33.

42. Collins SJ, Gallo RC, Gallagher RE. Continuous growth and differentiation of human myeloid leukaemic cells in suspension culture. Nature. 1977;270:347-9.

43. Matsuo Y, MacLeod RA, Uphoff CC, Drexler HG, Nishizaki C, Katayama Y, et al. Two acute monocytic leukemia (AML-M5a) cell lines (MOLM-13 and MOLM-14) with interclonal phenotypic heterogeneity showing MLL-AF9 fusion resulting from an occult chromosome insertion, ins(11;9)(q23;p22p23). Leukemia. 1997;11:1469-77.

44. Bose P, Gandhi V, Konopleva M. Pathways and mechanisms of venetoclax resistance. Leuk Lymphoma. 2017;58:1-17.

45. Chen X, Glytsou C, Zhou H, Narang S, Reyna DE, Lopez A, et al. Targeting mitochondrial structure sensitizes acute myeloid leukemia to venetoclax treatment. Cancer Disco. 2019;9:890-909.

46. Quesada V, Conde L, Villamor N, Ordonez GR, Jares P, Bassaganyas L, et al. Exome sequencing identifies recurrent mutations of the splicing factor SF3B1 gene in chronic lymphocytic leukemia. Nat Genet. 2011;44:47-52.

47. Kurtovic-Kozaric A, Przychodzen B, Singh J, Konarska MM, Clemente MJ, Otrock ZK, et al. PRPF8 defects cause missplicing in myeloid malignancies. Leukemia. 2015;29:126-36.

48. Farge T, Saland E, de Toni F, Aroua N, Hosseini M, Perry R, et al. Chemotherapyresistant human acute myeloid leukemia cells are not enriched for leukemic stem cells but require oxidative metabolism. Cancer Disco. 2017;7:716-35.

49. Panina SB, Baran N, Brasil da Costa FH, Konopleva M, Kirienko NV. A mechanism for increased sensitivity of acute myeloid leukemia to mitotoxic drugs. Cell Death Dis. 2019;10:617.

50. Basak NP, Banerjee S. Mitochondrial dependency in progression of acute myeloid leukemia. Mitochondrion. 2015;21:41-8.

51. Heinz S, Freyberger A, Lawrenz B, Schladt L, Schmuck G, Ellinger-Ziegelbauer H. Mechanistic investigations of the mitochondrial complex $\mathrm{i}$ inhibitor rotenone in the context of pharmacological and safety evaluation. Sci Rep. 2017;7:45465.

52. Konopleva MY. Mechanisms for resistance in AML insights into molecular pathways mediating resistance to venetoclax. Best $\mathrm{Pr}$ Res Clin Haematol. 2021;34:101251.

53. Maleki Y, Alahbakhshi Z, Heidari Z, Moradi MT, Rahimi Z, Yari K, et al. NOTCH1, SF3B1, MDM2 and MYD88 mutations in patients with chronic lymphocytic leukemia. Oncol Lett. 2019;17:4016-23.

54. Foy A, McMullin MF. Somatic SF3B1 mutations in myelodysplastic syndrome with ring sideroblasts and chronic lymphocytic leukaemia. J Clin Pathol. 2019;72:778-82. 
55. Choi HW, Kim HR, Baek HJ, Kook H, Cho D, Shin JH, et al. Alteration of the SETBP1 gene and splicing pathway genes SF3B1, U2AF1, and SRSF2 in childhood acute myeloid leukemia. Ann Lab Med. 2015;35:118-22.

56. Bamopoulos SA, Batcha AMN, Jurinovic $V$, Rothenberg-Thurley $M$, Janke $H_{t}$ Ksienzyk B, et al. Clinical presentation and differential splicing of SRSF2, U2AF1 and SF3B1 mutations in patients with acute myeloid leukemia. Leukemia. 2020;34:2621-34.

57. Agrawal AA, Seiler M, Brinton LT, Mantel R, Lapalombella R, Woyach JA, et al. Novel SF3B1 in-frame deletions result in aberrant RNA splicing in CLL patients. Blood Adv. 2017;1:995-1000.

58. Zhang $P$, Zhang $Y$, Li X, Ying P, Tang Y. U2AF1 expression is a novel and independent prognostic indicator of childhood T-lineage acute lymphoblastic leukemia. Int J Lab Hematol. 2021;43:675-82.

59. Okeyo-Owuor T, White BS, Chatrikhi R, Mohan DR, Kim S, Griffith M, et al. U2AF1 mutations alter sequence specificity of pre-mRNA binding and splicing. Leukemia. 2015;29:909-17.

60. Hong JY, Seo JY, Kim SH, Jung HA, Park S, Kim K, et al. Mutations in the spliceosomal machinery genes SRSF2, U2AF1, and ZRSR2 and response to decitabine in myelodysplastic syndrome. Anticancer Res. 2015;35:3081-9.

\section{ACKNOWLEDGEMENTS}

We would like to thank the UNMC Flow Cytometry Research Facility, UNMC Electron Microscopy Core, and UNMC Mass Spectrometry and Proteomics Core Facility for expert assistance. The core facilities are administrated through the Office of the Vice Chancellor for Research and supported by state funds from the Nebraska Research Initiative (NRI) and The Fred and Pamela Buffett Cancer Center's National Cancer Institute Cancer Support Grant. We would also like to thank Dr. Steve Caplan and Dr. Naava Naslavsky for their expertise in immunofluorescence experiments, Dr. Jim Wahl for experimental assistance and advice, and Erin McIntyre for assisting with Seahorse experiments. Human CD34 ${ }^{+}$cells were available with the support of Cooperative Centers of Excellence in Hematology NIDDK Grant \# DK106829. M.C. was supported by National Institute for General Medical Science (NIGMS) INBRE - P20GM103427-19. S.M.B. is supported by the National Institutes of Health P20GM121316, 1R37CA262635-01, and 1R01Al53090-01A1. This research was supported by the State of Nebraska through the Pediatric Cancer Research Group, part of the Child Health Research Institute. R.W.H. was supported by the UNMC NIH training grant (5T32CA009476-23). This publication was supported by the Fred \& Pamela Buffett Cancer Center Support Grant from the National Cancer Institute under award number P30 CA036727.

\section{AUTHOR CONTRIBUTIONS}

MC and SMB conceived and designed the experiments. MC, KJW, SAS, KKW, TJG, RWH and SMB performed experiments and analysis. MC and SMB wrote the manuscript. All authors reviewed the manuscript before submission.

\section{COMPETING INTERESTS}

The authors declare no competing interests.

\section{ADDITIONAL INFORMATION}

Supplementary information The online version contains supplementary material available at https://doi.org/10.1038/s41375-022-01518-z.

Correspondence and requests for materials should be addressed to Shannon $M$. Buckley.

Reprints and permission information is available at http://www.nature.com/ reprints

Publisher's note Springer Nature remains neutral with regard to jurisdictional claims in published maps and institutional affiliations.

\begin{abstract}
(c) (i) Open Access This article is licensed under a Creative Common Attribution 4.0 International License, which permits use, sharing adaptation, distribution and reproduction in any medium or format, as long as you give appropriate credit to the original author(s) and the source, provide a link to the Creative Commons license, and indicate if changes were made. The images or other third party material in this article are included in the article's Creative Commons license, unless indicated otherwise in a credit line to the material. If material is not included in the article's Creative Commons license and your intended use is not permitted by statutory regulation or exceeds the permitted use, you will need to obtain permission directly from the copyright holder. To view a copy of this license, visit http://creativecommons. org/licenses/by/4.0/.
\end{abstract}

(c) The Author(s) 2022 